\title{
Three-Dimensional Echocardiographic Analysis of Left Ventricular Function during Hemodialysis
}

\author{
Boudewijn J. Krenning $^{a} \quad$ Marco M. Voormolen ${ }^{a}$ Marcel L. Geleijnse ${ }^{a}$ \\ Anton F.W. van der Steen ${ }^{a}$ Folkert J. ten Cate ${ }^{a}$ Eric H.Y. le ${ }^{b} \quad J o s$ R.T.C. Roelandt ${ }^{a}$ \\ Departments of ${ }^{\mathrm{a}}$ Cardiology, Thorax Center, and ${ }^{\mathrm{b}}$ Medicine, Erasmus Medical Center, Rotterdam, The Netherlands
}

\section{Key Words}

Diagnosis $\cdot$ Hemodialysis $\cdot$ Left ventricular function

\begin{abstract}
Background: The effects of hemodialysis (HD) on left ventricular (LV) function have been studied by various echocardiographic techniques (M-mode, 2D echocardiography). These studies are hampered by a low accuracy of measurements because of geometric assumptions regarding LV shape. Three-dimensional echocardiography (3DE) overcomes this limitation. Methods: We tested the feasibility of 3DE assessment of LV function during HD. Conventional biplane Simpson rule (BSR) and single plane area length method (SPM) for LV function analysis were used as a reference. Results: $12 \mathrm{HD}$ patients were studied and in $10(83 \%)$ a total of 80 3D datasets were acquired. In 3 patients, one dataset (4\%) was of insufficient quality and excluded from analysis. Correlation between SPM, BSR and 3DE for calculation of end-diastolic (EDV, $r=0.89$ and $r=0.92$, respectively), endsystolic volume (ESV, $r=0.92$ and $r=0.93$, respectively) and for ejection fraction ( $E F, r=0.90$ and $r=0.88$, respectively) was moderate. Limits-of-agreement results for EDV and ESV were poor with confidence intervals larger than $30 \mathrm{ml}$. Both 2DE methods underestimated end-diastolic and end-systolic volume, while overestimating ejection fraction. Conclusion: $3 D E$ is feasible for image acquisition during $H D$, which opens the possibility for accurate and reproducible mea-
\end{abstract}

surement of LV function during HD. This may improve the assessment of the acute effect of HD on LV performance, and guide therapeutic strategies aimed at preventing intradialytic hypotension.

Copyright $\odot 2007$ S. Karger AG, Basel

\section{Introduction}

Intradialytic hypotension is an important complication of hemodialysis (HD). Although its pathogenesis is not completely understood, it is clear that the decrease in blood volume due to ultrafiltration is the most important initiating factor. Hypotension results from a decreased product of stroke volume (SV), heart rate (HR) and systemic vascular resistance. The continuing volume withdrawal during HD is a hemodynamic challenge which may lead to an inability to generate sufficient cardiac output $(\mathrm{CO})$. However, there is a large inter- and intraindividual variability regarding the incidence of intradialytic hypotension. Therefore, to better understand the interplay between progressive volume withdrawal and changes in $\mathrm{LV}$ performance during $\mathrm{HD}$, studies have been conducted using various echocardiographic techniques, including M-mode echocardiography [1, 2], two-dimensional echocardiography (2DE) $[3,4]$ and Doppler imaging [5-7]. Nevertheless, the acute effect of HD on cardiac function remains poorly understood, due to conflicting

\section{KARGER \\ Fax +4161306 1234 E-Mail karger@karger.ch} www.karger.com (c) 2007 S. Karger AG, Basel $1660-2110 / 07 / 1072-0043 \$ 23.50 / 0$

Accessible online at:

www.karger.com/nec
B.J. Krenning

Erasmus MC, Thorax Center, Room Ee 2302

Dr. Molewaterplein 40

NL-3015 GD Rotterdam (The Netherlands)

Tel. +31 104639 222, Fax +31 104362 995, E-Mail b.krenning@erasmusmc.nl 
results. A number of factors influence cardiac function measurements, such as loading conditions $[7,8]$. Earlier LV performance studies may have been hampered by a low accuracy of measurements. M-mode and 2D echocardiography are limited by geometric assumptions as to volume and function calculation. Three-dimensional echocardiography (3DE) overcomes this limitation, and has recently become a feasible method for rapid and accurate measurement of LV function in a clinical rather than research setting [9]. In this study, we therefore evaluate the feasibility of $3 \mathrm{DE}$ assessment of LV function during HD. Also, we compared our 3D results with conventional 2D methods for LV function analysis.

\section{Methods}

\section{Patients}

Twelve patients on chronic intermittent HD entered the study. Two patients were excluded because of insufficient 3D echocardiographic image quality. The remaining 10 patients had a mean age of $56 \pm 15$ years. All patients were in sinus rhythm and were dialyzed three times a week according to a standard dialysis program, which had been unchanged for three months or longer. No medication was discontinued for this study. Four patients had a history of cardiac disease (2 coronary interventions, 1 myocardial infarction, 1 angina pectoris). The mean heart rate (SD) during echocardiographic examination was $68 \pm 10 \mathrm{bpm}$. All patients gave informed verbal consent.

\section{Hemodialysis}

All dialysis treatments used Fresenius 4008 machines (Fresenius Medical Care, Bad Homburg, Germany), biocompatible membranes (Hemophane or Polysulphone) and bicarbonatebuffered dialysate (Fresenius Medical Care SK-F213). The duration of the dialysis procedure was $4 \mathrm{~h}$ in all patients. During the first 30 min patients were connected to the dialysis machine with only blood flow (recirculation) but no HD or ultrafiltration (UF) taking place. The mean amount of fluid withdrawn was 2,617 \pm $1,088 \mathrm{ml}$.

\section{Three-Dimensional Echocardiography}

We used a new prototype transthoracic, fast-rotating 64-element array transducer with a center frequency of $3 \mathrm{MHz}$. Technical aspects have been described elsewhere [10]. In short, this transducer features the capability of second harmonic imaging and continuously rotates around its central axis with a maximum rotation speed of 480 rotations per minute. The transducer is connected to a commercially available ultrasound system (GE Vingmed Vivid 5, Horton, Norway). A validation study using cardiac magnetic resonance imaging as a reference showed a strong correlation and good inter- and intra-observer agreement [11].

\section{Image Acquisition}

3DE was performed before $\mathrm{HD}, 5$ min after patient connection to the HD system, during recirculation without UF (after $30 \mathrm{~min}$ ), every hour during HD with UF, and 15 min after HD. In total, 8 acquisitions were performed in each patient. Patients were studied in a partial left lateral decubitus position during HD. The transducer was placed in the apical position with the image plane rotating around the LV long axis. The depth settings were adjusted to visualize the entire LV and part of the left atrium. Gain and power settings were optimized for endocardial border visualization. The image acquisition was made, in second harmonic imaging mode (transmit frequency: $2 \mathrm{MHz}$ ) during a single end-expiratory breath hold of approximately $10 \mathrm{~s}$ and the ECG was simultaneously recorded for the $3 \mathrm{D}$ reconstruction process.

Three-Dimensional Imaging Processing and Analysis

Imaging processing and analysis was performed as previously described [11]. Image data were transferred via a network connection to a dedicated PC for processing and analysis. With custom designed software, based on MatLab (The MathWorks Inc., Natick, Mass., USA), the original 2D images are post-processed into 3D datasets. Subsequently, TomTec ${ }^{\circledR} 4$-D LV-analysis software (TomTec Imaging Systems, Munich, Germany) was used for further analysis. Eight equidistant cross-sectional image planes were used for analysis. The orientation of these images in $3 \mathrm{D}$ space was determined by manually marking the mitral valve, aortic root and apex. Contrast and gain settings were adjusted for optimal endocardial border visualization. Subsequently, the software automatically performed endocardial border detection in all images. One investigator verified the results from the automated border detection and corrected if necessary.

The analysis program displays a reconstruction of the LV as a dynamic surface rendered image, in which LV wall motion is shown in three dimensions (fig. 1). From an automatically plotted volume-time curve, LV end-diastolic (EDV) and end-systolic volume (ESV) was determined by the maximal and minimal volume and ejection fraction (EF) was calculated.

Two-Dimensional Image Processing and Analysis

From the 3D dataset, two perpendicular images were extracted representing the apical 2D four- and two-chamber views. Manual endocardial border delineation was performed with MatLab using custom designed software. Two common algorithms for $2 \mathrm{DE}$ ventricular volume calculation were used, as recommended by the American Society of Echocardiography [12]:

(1) The disc summation method or biplane Simpson rule (BSR), based on orthogonal planes from apical two- and fourchamber views. Volumes were computed using the formulation:

$$
\text { Volume }=\frac{\pi}{4} \sum_{\mathrm{i}=1}^{20} \mathrm{a}_{\mathrm{i}} \mathrm{b}_{\mathrm{i}} \frac{\text { cavity length }}{20}
$$

where $\mathrm{a}$ and $\mathrm{b}$ represent diameters of discs (see fig. 2).

(2) The single plane area length method by calculation of LV end-diastolic and end-systolic volumes and ejection fractions from the four-chamber view. Volumes were computed using the formulation (fig. 2):

$$
\text { Volume }=0.85 \times \frac{(\text { cavity area })^{2}}{\text { cavity length }}
$$

Inter- and Intra-Observer Variability

To assess inter-observer variability for 2DE, the first two acquisitions of each patient were independently analyzed by another observer blinded to previous results. For assessment of intra-
Krenning/Voormolen/Geleijnse/ van der Steen/ten Cate/Ie/Roelandt 
Fig. 1. a The LV is divided into 8 equidistant cross-sectional images which are used for contour analysis. b An original image of an apical long axis view during fast rotation. Reconstruction of the LV in end diastole (c), and end systole (d).

Fig. 2. Top panel: Biplane Simpson rule for calculating LV volume, based on orthogonal planes from apical 2- and 4-chamber view. Bottom panel: Single plane area length method, based on a single apical view. Reprinted from Schiller et al. [12], with permission from The American Society of Echocardiography.

3D Echocardiography for LV Function during Hemodialysis
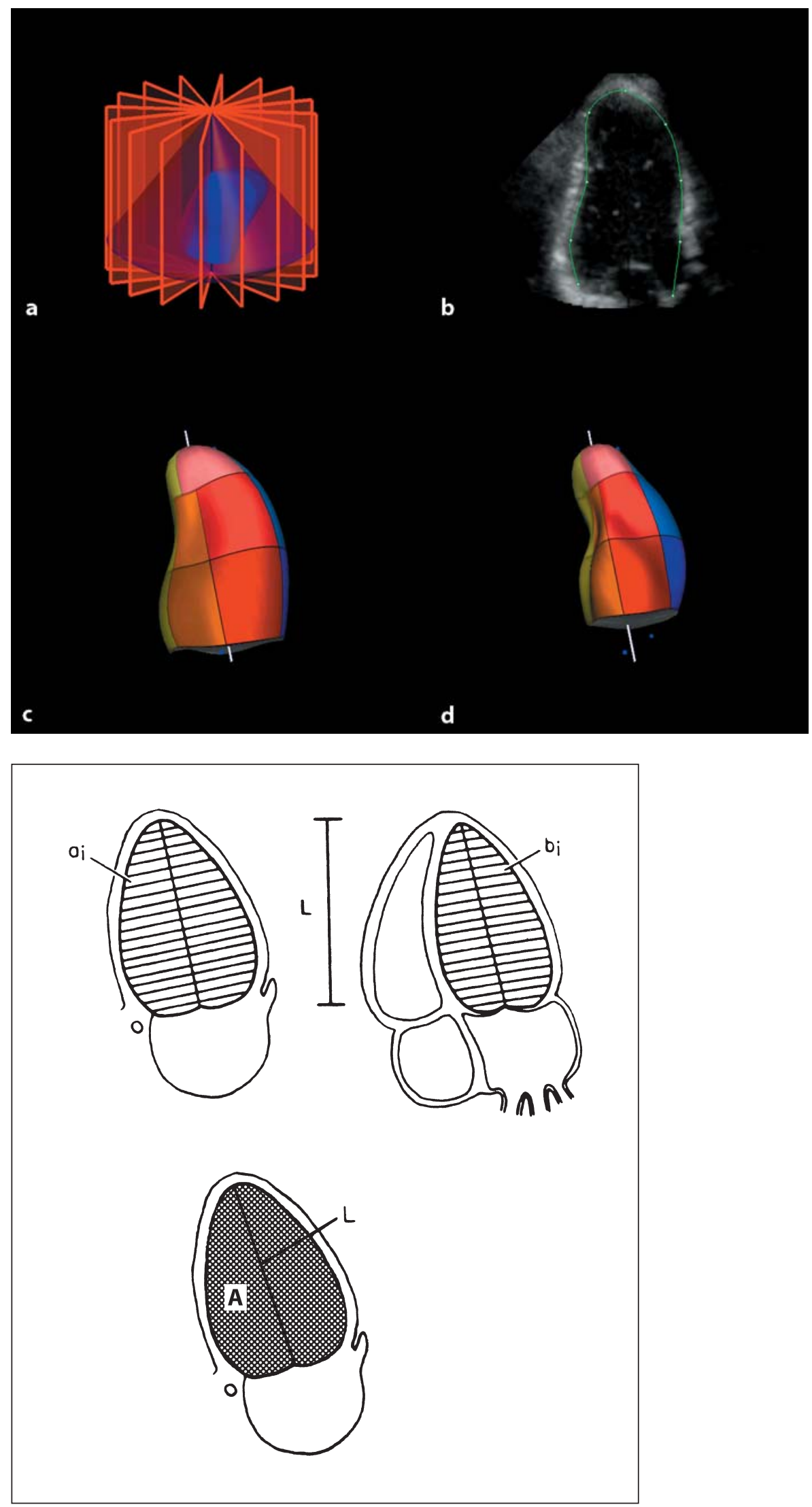

Nephron Clin Pract 2007;107:c43-c49 
Table 1. Comparison of LV volume and function measurement by 3DE and 2DE methods

\begin{tabular}{|c|c|c|c|c|c|}
\hline & $\mathrm{R}$ & Regression equation & SEE & $\begin{array}{l}\text { Mean difference } \\
\pm \mathrm{SD}\end{array}$ & $\begin{array}{l}\mathrm{t} \text { test vs. } 3 \mathrm{DE} \\
\text { ( } \mathrm{p} \text { value) }\end{array}$ \\
\hline \multicolumn{6}{|c|}{ Single plane method } \\
\hline $\mathrm{EDV}, \mathrm{ml}$ & 0.89 & $y=0.88 x-0.86$ & 23.12 & $-16.2 \pm 22.7$ & $<0.05$ \\
\hline $\mathrm{ESV}, \mathrm{ml}$ & 0.92 & $y=0.80 x+1.33$ & 15.43 & $-15.3 \pm 16.7$ & $<0.02$ \\
\hline $\mathrm{EF}, \%$ & 0.90 & $y=0.93 x+5.55$ & 4.87 & $3.1 \pm 4.6$ & NS \\
\hline \multicolumn{6}{|c|}{ Biplane Simpson } \\
\hline $\mathrm{EDV}, \mathrm{ml}$ & 0.92 & $y=0.85 x-3.04$ & 18.91 & $-21.9 \pm 19.4$ & $<0.01$ \\
\hline $\mathrm{ESV}, \mathrm{ml}$ & 0.93 & $y=0.82 x-1.57$ & 14.20 & $-16.8 \pm 15.4$ & $<0.01$ \\
\hline $\mathrm{EF}, \%$ & 0.88 & $y=0.92 x+4.60$ & 5.27 & $1.7 \pm 5.0$ & NS \\
\hline
\end{tabular}

Results of regression analysis and Bland-Altman analysis comparing LV volume and function with 3DE and 2DE methods (see text for details).

observer variability, the first observer repeated analysis in a random order. Both were blinded to 3DE results. Data on inter- and intra-observer variability for 3DE were available from a previous validation study [11].

\section{Statistical Analysis}

Results for EDV, ESV and EF are represented as mean and SD. Data was tested for normality with the Shapiro-Wilk test. A repeated-measures ANOVA was used for analysis of differences within the variations. Post-hoc testing was performed with the paired t test. Regression and limits of agreement analysis was performed for 3DE and 2DE measurements according to the method of Bland and Altman [13]. Results for inter- and intra-observer variations are represented as mean \pm SD for the difference between the two measurements. $\mathrm{p}<0.05$ was considered to be significant.

\section{Results}

Successful image acquisition was achieved in 10/12 patients $(83 \%)$. A total of $803 \mathrm{D}$ datasets were acquired in these 10 patients. In 3 patients, one dataset (4\%) was of insufficient quality and excluded from analysis. One patient suffered from symptomatic hypotension during $\mathrm{HD}$, although no intervention was required. The time for data analysis averaged $15 \pm 5$ min per 3D dataset.

The test for normality was not significant, indicating that the data did not significantly deviate from the normal distribution. Repeated measures ANOVA showed a significant difference between the measurement methods $(\mathrm{F}=10.5 ; \mathrm{p}<0.02)$ but no significant difference between the moment of measurement $(F=0.57, p<0.78)$. Because a significant effect in time was not found, the data was averaged for further analysis.
Correlation between the 2DE methods and 3DE for EDV $(r<0.92)$, ESV $(r<0.93)$ and EF $(r<0.90)$ was moderate (fig. 3). However, the limits-of-agreement between methods for EDV and ESV were poor with confidence intervals all larger than $30 \mathrm{ml}$ (table 1). ANOVA analysis for EDV, ESV and EF showed significant differences between the different measurement methods $(\mathrm{F}=$ $8.4, \mathrm{p}<0.005)$. Post-hoc testing showed that both $2 \mathrm{DE}$ methods significantly underestimated EDV and ESV compared to 3DE. Limits-of-agreement analysis for EF showed an overestimation for both $2 \mathrm{DE}$ methods. However, these differences were not significant compared to 3DE.

\section{Inter-and Intra-Observer Variability}

The limits of agreement analysis of 3DE data from measurements performed by the first observer showed a mean difference of $-1.4 \pm 6.6 \mathrm{ml}$ for EDV, $-0.1 \pm 4.4 \mathrm{ml}$ for ESV and $-0.3 \pm 2.4 \%$ for EF. For 2DE using SPM, the results were $-1.2 \pm 11.4 \mathrm{ml},-3.2 \pm 16.0 \mathrm{ml}$ and $1.6 \pm$ $10.6 \%$, respectively. For 2DE using BSR, the results were $3.9 \pm 13.9 \mathrm{ml}, 1.7 \pm 15.2 \mathrm{ml}$ and $0 \pm 10.5 \%$, respectively.

The limits of agreement analysis demonstrated a mean difference of $-0.1 \pm 11.7 \mathrm{ml}$ for LVEDV, $1.3 \pm 8.7$ $\mathrm{ml}$ for LVESV and $-0.7 \pm 4.8 \%$ for LVEF, for 3DE data by two independent observers. For 2DE using SPM, the results were $0.3 \pm 8.1 \mathrm{ml},-10.6 \pm 22.3 \mathrm{ml}$ and $7.1 \pm$ $14 \%$, respectively. For $2 \mathrm{DE}$ using BSR, the results were $-3.4 \pm 14.7 \mathrm{ml},-2.5 \pm 16.4 \mathrm{ml}$ and $1.0 \pm 10.3 \%$, respectively. 
Fig. 3. Relation between $3 \mathrm{DE}$ and $2 \mathrm{DE}$ measurements of EDV, ESV, and EF. The left panels show the regression analysis between the two methods. Dashed lines delimit 95\% confidence interval. $\boldsymbol{\Delta}$, solid line = Biplane Simpson method; $\bigcirc$, dashed line = single plane area length method. The right panels show plots of the difference between $3 \mathrm{DE}$ and $2 \mathrm{DE}$, as a function of the average calculated volumes. Solid and dashed lines represent mean \pm 2 SDs of the difference, respectively. $\mathrm{EDV}=$ Left ventricular end-diastolic volume; $\mathrm{EF}=$ left ventricular ejection fraction; ESV = left ventricular endsystolic volume.
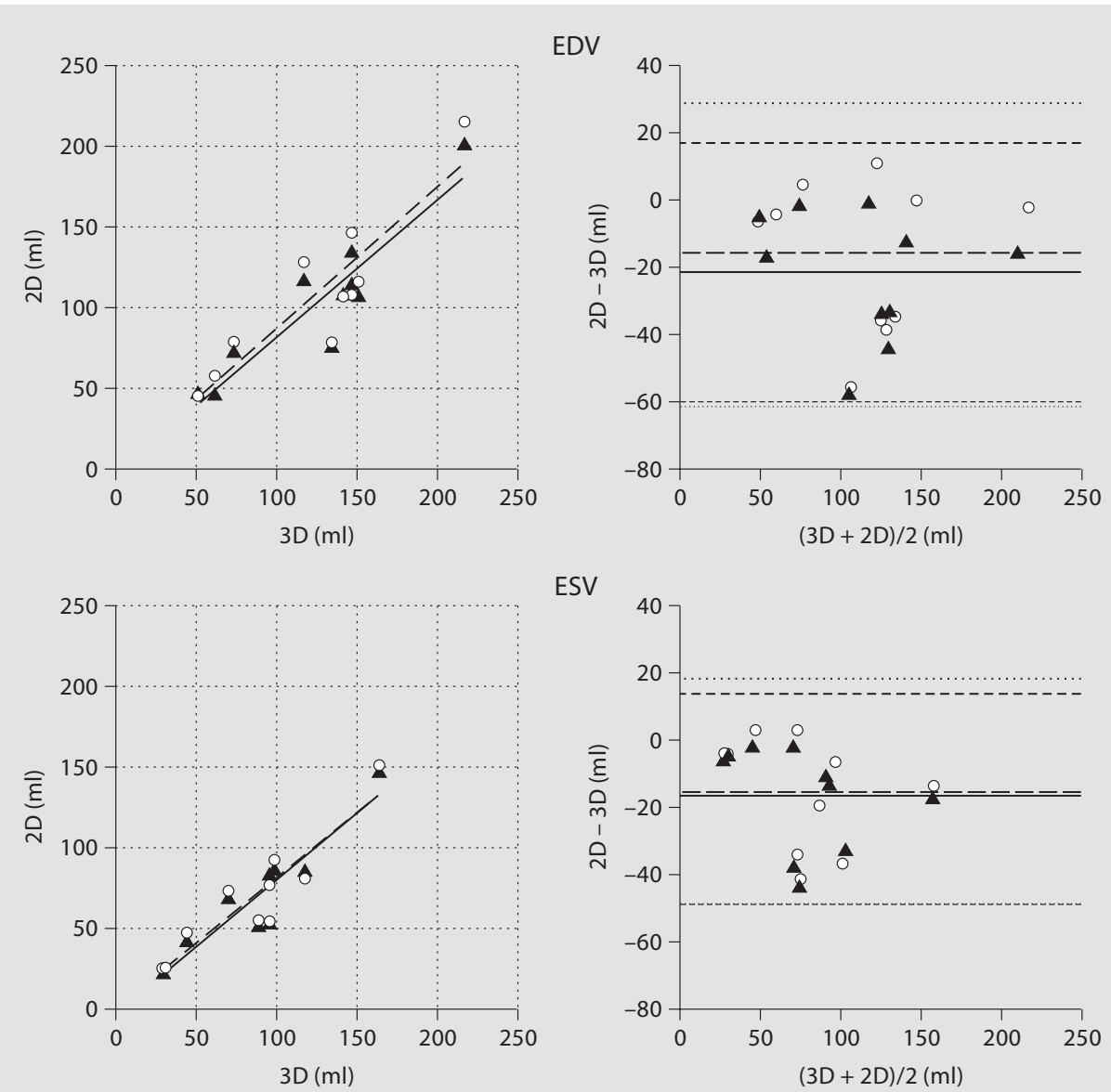

ESV
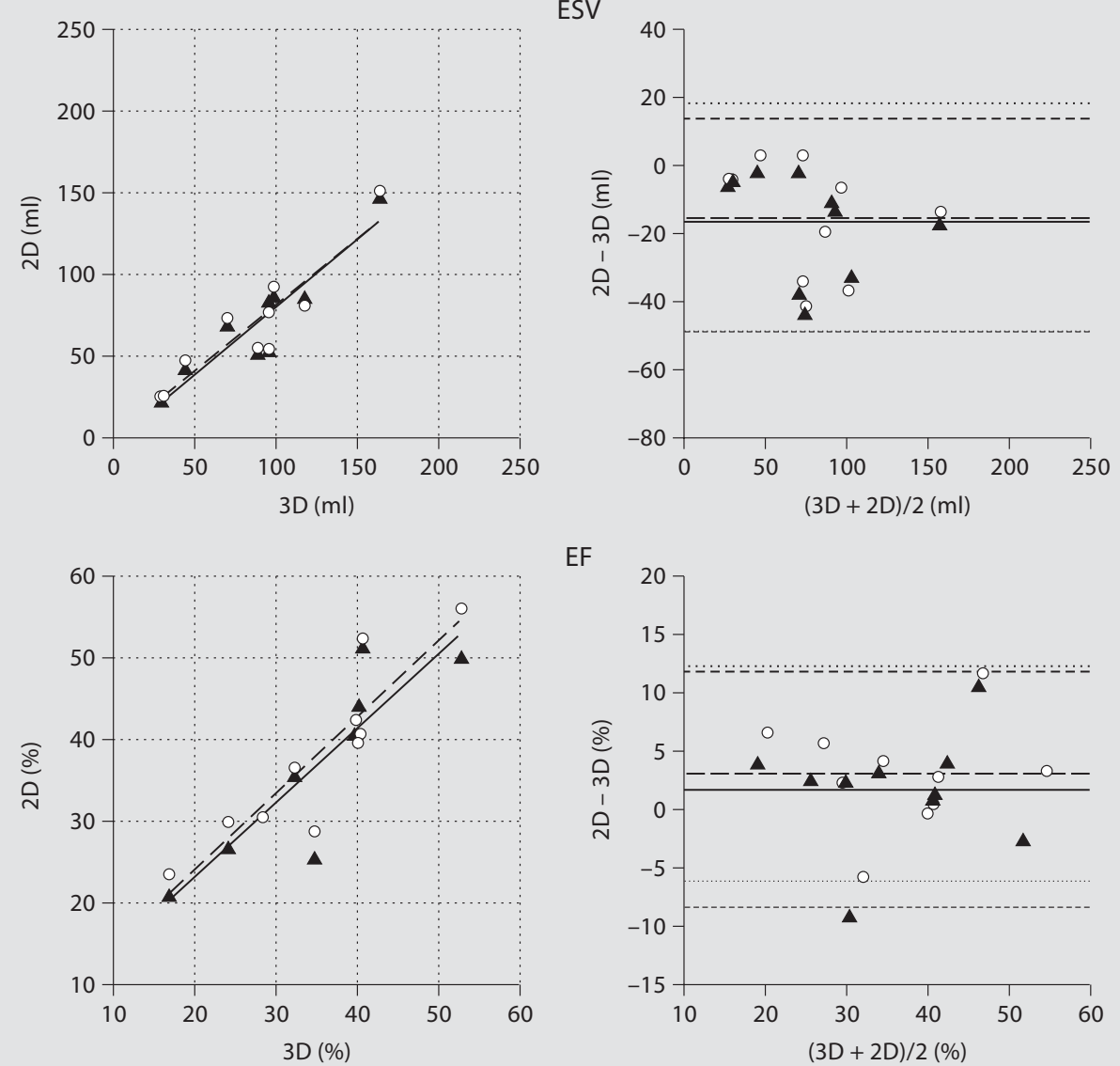

EF

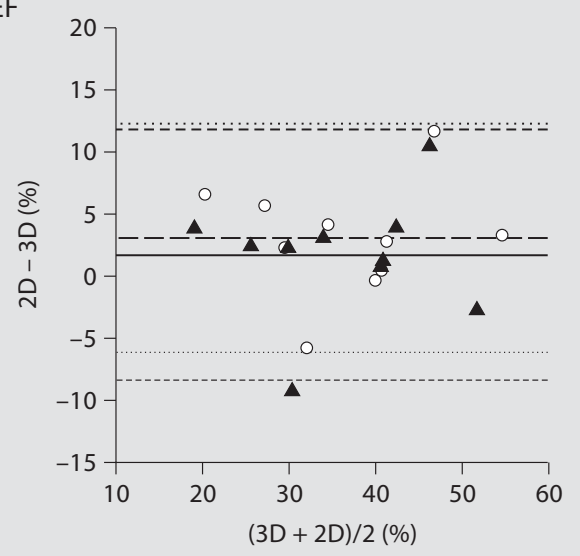

\section{Discussion}

This study demonstrates that image acquisition using $3 \mathrm{DE}$ is feasible for accurate evaluation of LV function in patients during HD. Previous studies showed that 3DE calculates LV volume with a precision comparable to car- diac magnetic resonance imaging $[11,14,15]$. While both techniques are superior to $2 \mathrm{DE}$, magnetic resonance imaging is not feasible during HD. Tissue Doppler imaging (TDI), a newer Doppler technique advocated as less loaddependent [16, 17], can be used during HD [18]. TDI primarily yields information on myocardial contraction and 
relaxation, but is less used for assessment of overall LV performance, which is usually expressed using the wellknown parameters SV and ejection fraction.

The large interval between the limits of agreement and the underestimation of $L V$ volume by $2 \mathrm{DE}$ are in line with previous reports $[14,19]$. 2DE calculations of LV function using the disc-summation method is based on the assumption that a ventricle can be represented by a series of stacked elliptic discs of varying diameters. In patients with regional wall motion abnormalities and deformed ventricles, this assumption may be unjustified and result in an inaccurate and poor reproducibility of $2 \mathrm{DE}$ measurements. Using 3DE, however, no assumption is made about the shape of the LV, and LV volume is calculated from a much greater set of data. Therefore, 2DE should be used with caution for LV function analysis when relatively small differences in LV volume are expected, as during $\mathrm{HD}$. When more image planes are used for LV volume calculation, as in $3 \mathrm{DE}$, an increase in accuracy is observed. Previous studies suggested that at least four to eight image planes are necessary to accurately represent the ventricular volume [20,21]. Nosir et al. [22] showed that a $1 \%$ change in $L V$ volume can be observed with a $90 \%$ likelihood when 8 image planes are used.

To our knowledge, this is the first study to use $3 \mathrm{DE}$ during HD. Only one study used 3DE in HD patients for LV function determination [23]. However, this study was not performed in the HD department. Accurately assessing the changes in LV volumes during HD can result in a better insight into the development of dialysis hypotension. Especially the role of the so-called Bezold-Jarisch reflex, which leads to bradycardiac hypotension believed to be triggered by a severely underfilled LV, is not well understood. Monitoring changes in LV filling may help predicting the onset of hypotension, and may guide therapeutic strategies such as ultrafiltration profiling. Additionally, more reproducible assessment of LV volumes, function and mass helps cardiovascular risk stratification, which is important not only for managing the di- alysis population but also for the work-up of renal transplant candidates among dialysis patients.

Our study is limited by the small number of patients. However, this study was not designed to determine the effect of a single HD session on LV performance. During image acquisition, a partial left lateral decubitus position and $10 \mathrm{~s}$ breath-hold were required. This was well-tolerated by the HD patients in our study. 3DE relies on achieving good endocardial border definition which depends on various factors. As patients in the HD department cannot be positioned in the most optimal way as they are in the echocardiography department (because of interference with blood lines, absence of examination table), this could hamper optimal image quality. Although effort was required by patient and ultrasonographist, we could acquire sufficient image quality in $80 \%$ of patients. In only 3 patients was a single acquisition of insufficient quality. Previous studies have shown an improvement in image quality [24] and, subsequently, smaller limits of agreement in inter- and intra-observer variability when intravenous ultrasound contrast agents are used $[25,26]$. Further studies are necessary to evaluate the feasibility thereof in this patient population.

\section{Conclusion}

We conclude that successful image acquisition for 3DE is feasible for accurate and reproducible measurement of LV function during HD. This may improve the assessment of the acute effect of HD on cardiac function, and guide therapeutic strategies aimed at preventing intradialytic hypotension.

\section{Acknowledgement}

We would like to thank Jerome Borsboom for his assistance in the statistical analysis.

\section{References}

1 Chaignon M, Chen WT, Tarazi RC, Nakamoto S, Salcedo E: Acute effects of hemodialysis on echographic-determined cardiac performance: improved contractility resulting from serum increased calcium with reduced potassium despite hypovolemic-reduced cardiac output. Am Heart J 1982;103: 374-378.
2 Cohen MV, Diaz P, Scheuer J: Echocardiographic assessment of left ventricular function in patients with chronic uremia. Clin Nephrol 1979;12:156-162.

3 Bornstein A, Gaasch WH, Harrington J: Assessment of the cardiac effects of hemodialysis with systolic time intervals and echocardiography. Am J Cardiol 1983;51:332-335. 
4 Zoccali C, Benedetto FA, Mallamaci F, Tripepi G, Giacone G, Cataliotti A, Seminara G, Stancanelli B, Malatino LS: Prognostic value of echocardiographic indicators of left ventricular systolic function in asymptomatic dialysis patients. J Am Soc Nephrol 2004;15: 1029-1037.

5 Gupta S, Dev V, Kumar MV, Dash SC: Left ventricular diastolic function in end-stage renal disease and the impact of hemodialysis. Am J Cardiol 1993;71:1427-1430.

6 Galetta F, Cupisti A, Franzoni F, Carpi A, Barsotti G, Santoro G: Acute effects of hemodialysis on left ventricular function evaluated by tissue Doppler imaging. Biomed Pharmacother 2006;60:66-70.

7 Ie EH, Vletter WB, ten Cate FJ, Nette RW, Weimar W, Roelandt JR, Zietse R: Preload dependence of new Doppler techniques limits their utility for left ventricular diastolic function assessment in hemodialysis patients. J Am Soc Nephrol 2003;14:18581862.

8 Tomson CR: Echocardiographic assessment of systolic function in dialysis patients. Nephrol Dial Transplant 1990;5:325-331.

9 Monaghan MJ: Role of real time 3D echocardiography in evaluating the left ventricle. Heart 2006;92:131-136.

10 Voormolen MM, Bouakaz A, Krenning BJ, Lancee CT, ten Cate FJ, Roelandt JRTC, van der Steen AFW, de Jong N: A new transducer for 3D harmonic imaging. Proc IEEE Int Ultrasonics Symp, Munich, 2002, vol 2, pp 1261-1264.

11 Krenning BJ, Voormolen MM, van Geuns RJ, Vletter WB, Lancee CT, de Jong N, Ten Cate FJ, van der Steen AF, Roelandt JR: Rapid and accurate measurement of left ventricular function with a new second-harmonic fastrotating transducer and semi-automated border detection. Echocardiography 2006; 23:447-454.
12 Schiller NB, Shah PM, Crawford M, DeMaria A, Devereux R, Feigenbaum H, Gutgesell H, Reichek N, Sahn D, Schnittger I, et al: Recommendations for quantitation of the left ventricle by two-dimensional echocardiography. American Society of Echocardiography Committee on Standards, Subcommittee on Quantitation of TwoDimensional Echocardiograms. J Am Soc Echocardiogr 1989;2:358-367.

13 Bland JM, Altman DG: Statistical methods for assessing agreement between two methods of clinical measurement. Lancet 1986;i: 307-310.

14 Gutierrez-Chico JL, Zamorano JL, Perez de Isla L, Orejas M, Almeria C, Rodrigo JL, Ferreiros J, Serra V, Macaya C: Comparison of left ventricular volumes and ejection fractions measured by three-dimensional echocardiography versus by two-dimensional echocardiography and cardiac magnetic resonance in patients with various cardiomyopathies. Am J Cardiol 2005;95:809-813.

15 Corsi C, Lang RM, Veronesi F, Weinert L, Caiani EG, MacEneaney P, Lamberti C, MorAvi V: Volumetric quantification of global and regional left ventricular function from real-time three-dimensional echocardiographic images. Circulation 2005;112:11611170.

16 Sharma R, Pellerin D, Gaze DC, Mehta RL, Gregson H, Streather CP, Collinson PO, Brecker SJ: Mitral peak Doppler E-wave to peak mitral annulus velocity ratio is an accurate estimate of left ventricular filling pressure and predicts mortality in end-stage renal disease. J Am Soc Echocardiogr 2006; 19:266-273.

17 Barberato SH, Mantilla DE, Misocami MA, Goncalves SM, Bignelli AT, Riella MC, Pecoits-Filho R: Effect of preload reduction by hemodialysis on left atrial volume and echocardiographic Doppler parameters in patients with end-stage renal disease. Am J Cardiol 2004;94:1208-1210.

18 Ie EH, Zietse R: Evaluation of cardiac function in the dialysis patient: a primer for the non-expert. Nephrol Dial Transplant 2006; 21:1474-1481.

19 Jenkins C, Bricknell K, Hanekom L, Marwick TH: Reproducibility and accuracy of echocardiographic measurements of left ventricular parameters using real-time three-dimensional echocardiography. J Am Coll Cardiol 2004;44:878-886.
20 Tanabe K, Belohlavek M, Jakrapanichakul D, Bae RY, Greenleaf JF, Seward JB: Three-dimensional echocardiography: precision and accuracy of left ventricular volume measurement using rotational geometry with variable numbers of slice resolution. Echocardiography 1998;15:575-580.

21 Siu SC, Rivera JM, Handschumacher MD, Weyman AE, Levine RA, Picard MH: Threedimensional echocardiography: the influence of number of component images on accuracy of left ventricular volume quantitation. J Am Soc Echocardiogr 1996;9: 147-155.

22 Nosir YF, Vletter WB, Kasprzak JD, Boersma E, Lequin MH, Elhendy AA, Yao J, Stoker J, Ten Cate FJ, Roelandt JR: Optimal rotational interval for 3-dimensional echocardiography data acquisition for rapid and accurate measurement of left ventricular function. J Am Soc Echocardiogr 2000;13: 715-722.

23 Fathi R, Isbel N, Haluska B, Case C, Johnson DW, Marwick TH: Correlates of subclinical left ventricular dysfunction in ESRD. Am J Kidney Dis 2003;41:1016-1025.

24 Kasprzak JD, Paelinck B, Ten Cate FJ, Vletter WB, de Jong N, Poldermans D, Elhendy A, Bouakaz A, Roelandt JR: Comparison of native and contrast-enhanced harmonic echocardiography for visualization of left ventricular endocardial border. Am J Cardiol 1999;83:211-217.

$25 \mathrm{Yu} \mathrm{EH}$, Sloggett CE, Iwanochko RM, Rakowski H, Siu SC: Feasibility and accuracy of left ventricular volumes and ejection fraction determination by fundamental, tissue harmonic, and intravenous contrast imaging in difficult-to-image patients. J Am Soc Echocardiogr 2000;13:216-224.

26 Malm S, Frigstad S, Sagberg E, Larsson H, Skjaerpe T: Accurate and reproducible measurement of left ventricular volume and ejection fraction by contrast echocardiography: a comparison with magnetic resonance imaging. J Am Coll Cardiol 2004;44:10301035. 